GENE REGULATION

\section{Grouped in silence}

Nuclear subdomains that contain Polycomb group ( $\mathrm{PcG}$ ) bodies are known to silence gene activity — but do they do so directly, by binding of PcG proteins to target promoters, or indirectly, by compartmentalizing the target genes into the repressive subdomain? A study in flies shows that the epigenetic silencing of Hox genes by $\mathrm{PcG}$ proteins is mediated by the genes' three-dimensional proximity in the nucleus.

The identity of anterior-posterior fly body segments is maintained by the repression of particular Hox genes by PcG proteins in spatially distinct domains. Using fluorescent in situ hybridization and immunostaining to Polycomb, Bantignies and colleagues found that Hox genes colocalize in PcG bodies, but only in those regions of the embryo or larva in which the Hox genes are repressed. Colocalization depends on PcG proteins and involves target genes - for example, Antennapedia (Antp) and Abdominal-B $(A b d B)$ - that are up to $10 \mathrm{Mb}$ apart.

Chromosome conformation capture on chip experiments confirmed the presence of long-range interactions: the chromosomal contact between Antp and $A b d B$ was mediated by two $A b d B$ PcG response elements (PREs), Fab7 and Mcp. When $\mathrm{Fab7}$ is mutated, the expression of several genes, including Antp, is derepressed. This interaction between Antp and AbdB PREs is also physiologically relevant: target PREs have a PcG-dependent epigenetic mark and, in vivo, Fab7 or Mcp mutations enhance the homeotic phenotype of a sensitized Antp allele.

The long-range interactions seen in PcG bodies may be a new form of regulatory mechanism that depends on nuclear positioning. It remains to be seen whether the PREs of other genes show similar relationships.

Tanita Casci $\begin{array}{ll}\text { Anterior Posterior } & \end{array}$

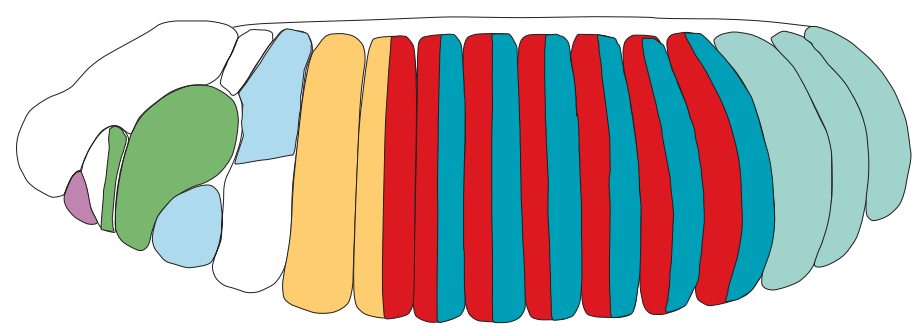

lab $p b$ Dfd $\mathrm{Scr}$ Antp Ubx

Modified, with permission, from Pearson, J. C., Lemons, D. \& McGinnis, W. Modulating Hox gene functions during animal body patterning. Nature Rev. Genet. 6, 893-904 (2005) @ Macmillan Publishers Ltd. All rights reserved. 